\title{
AN INFORMAL MEETING OF ICCA MEMBERS
}

\author{
Cape May, N.J., 27 June 1994 \\ Tony Marsland ${ }^{l}$ \\ ICCA President
}

On Monday 27 June, 1994, from 16:30 to 18:00, the participants at the $24^{\text {th }}$ ACM International Computer Chess Championship at Cape May, N.J., met with representatives of the ICCA. They reviewed the status of computer chess and provided some insights and views into the ICCA's present and future activities. ICCA President Tony Marsland represented the ICCA, supported by the tournament officials Monty Newborn and Mike Valvo.

The meeting was necessarily informal, even though chaired by the ICCA President. This has the advantage of a free airing of news and views and the drawback of a lack of commitment. So be it. We shall report what transpired fairly, but necessarily selectively.

The next few years, it was held, will be active ones for computer chess, since there is growing pressure for and interest in a match between the best computer program and the World Chess Champion. The ICCA by its constitution is especially interested in the advancement and development of all chess-playing programs. The President noted that in recent years the main growth had been in microcomputer chess machines. Also, the many and varied events in Europe have led to a dramatic improvement of chess programs there. Partly this is because of greater European interest in chess (a common motif in store-window displays), as evidenced by the many recent World microcomputer chess events (e.g., Munich, November 1993), the AEGON Tournament (humans vs. computers) in The Hague each May, and local events such as the Dutch Championship, each October, and the tournament sponsored by Paderborn University, also each October. The President found that similar events did not occur in America quite as frequently, though there is the Harvard Cup (a poor cousin of AEGON and perhaps trying too hard to ensure some good results against "tired" humans), the USCF involvement in the rating of programs, and of course the premier event here the ACM International Computer-Chess Championship.

The prospects for a 1994 World Microcomputer Chess Championship (WMCC) are not bright, though there is some interest from the University of Bologna in Italy for a WMCC tournament-cum-conference in 1995. For next year, the SPAA Conference [Santa Barbara, Cal., July 1995] has expressed its interest through Charles Leiserson; the ACM is also exploring the possibility of hosting an event in Nashville, Ten., late February 1995, and again in 1996 at Philadelphia. These dates correspond first to 25 years of ACM's support for computer chess, and second to the $50^{\text {th }}$ anniversary of ACM's founding. The general feeling was that the ICCA should continue to encourage the ACM's interest in computer chess, and to try to capitalize on these two anniversaries by helping to find suitable sponsors.

There are two other proposals in their early stages. It has been suggested that the $8^{\text {th }}$ triennial WCCC be in Germany in September 1995. Although this event has traditionally alternated between Europe and North America (the Madrid 1992 WCCC being the most recent), the ICCA is committed to accepting the first feasible proposal. This maximizes the time for participants to prepare themselves. One non-traditional suggestion for the WCCC is for an event in Hong Kong, with digital radio communication among sites elsewhere, forming a global demonstration of multi-media technology as well as of chess. Much will depend on the interest of sponsors - but time is short.

Some members noted that the Supercomputing conferences in New York and Albuquerque, N.M., had provided good locations and audiences, but those present noted they would be happy with any well-organized event.

\footnotetext{
Visiting Professor, Hong Kong University, Computer Science Department, Pokfulam Road, Hong Kong. Email: marsland@csd.hku.hk.
} 
The many members present at the meeting provided considerable feedback to the Board of ICCA and among many others they made the following observations:

1. A membership address list of ICCA members who are actively developing chess programs would be valuable, at the very least a list of email addresses. This need not to be a public list (except for those who expressedly opted for that), but should at least be available to registered developers. There seemed to be a genuine interest in better interactions among amateur software developers. The ICCA was invited to facilitate such communication. Dan Heisman, a long-time ICCA member, produced his 1978 membership list. He suggested that distributing a membership list is one more way of keeping our community together.

2. There was general appreciation for and interest in Don Beal's Uniform-Platform event. Details about the next event are circulating (see ICCA Journal Vol 17, No. 1, pp. 44-45 and this issue pp. 167-173); it was proposed that email messages to programmers and newsgroup announcements were the appropriate way to compensate for the short lead times. The ICCA Journal was criticized as barely providing enough advance notice for planning revisions, vacations and so on.

3. Although the loss of cash prizes at the ACM International Computer-Chess Championship was mourned, these prizes were not seen by Marty Hirsch and others as primary motivators for chess programmers. However, the feeling was also expressed that valuable prizes raise the stature of an event.

4. There was considerable discussion about how to involve potential sponsors. The names of senior executives in major potential sponsor firms, such as Intel and Motorola who have a known interest in chess were sought from the participants. There was an expressed belief that we must have a TV audience for our events and that we should have more dynamic displays and replays for commentators.

More public interactive displays were advocated. Also, perhaps the creation of an "auto-play" mode so that programmers could then serve as commentators of their programs (no longer having to serve moves!). Perhaps we could seek a sponsor from some multi-media company. Could we put together a record of past coverage, including newspaper clippings, event brochures and sample TV shots? Can we list the stations and locations which have provided coverage in the past? Unfortunately, the issue of how this might be done and by whom was not addressed.

5. Although the meeting was pleased with FRITZ3's recent success in a GM blitz tournament, it was disappointed that not more computers had been included. Clearly, chess programs are now competitive with the very best human players at blitz chess. Seeing this, the ICCA is urged to seek more opportunities for computers and humans to match wits, say by working with the PCA.

6. There was a proposal that the ICCA Journal should also be available in electronic form, say as a POSTSCRIPT file. This would reduce the mailing cost and could make the Journal available to subscribers much sooner. Merit and interest were seen in this idea, though leaving the longer-term implications unclear. Even so, the suggestion will be brought to the attention of the Editorial Board of the ICCA Journal.

7. There was little reported objection to an ICCA-membership-fee increase, even up to $\$ 60$. One major proponent, Steven Edwards, thought that an annual increase of $\$ 10$ would be more palatable to the average member than an immediate doubling of the fee. Of course it was realized that the members present were not a representative sample of our membership. Several members felt that some thought should be given to selling additional services (such as early email items), to encouraging corporate sponsorships at the present rates of $\$ 500$ and $\$ 1000$, to ensuring that events can be reliably planned without being unduly onerous on a site that has "volunteers" and "in-kind" contributions rather than cash.

Hal Bogner's suggestion was to licence winners of ICCA titles to use the ICCA logo on their packaging and to publish official notices of their titles. This idea is consistent with practice in other sports and certainly seems worth exploring.

It was also held that making ICCA Journal articles available to other publishers (on condition of full and appropriate acknowledgement) might attract more subscribers as well as heightening our profile. Republication of articles and reports by national chess organizations such as the USCF or magazines such as 
Computerschach und Spiele was also recommended.

8. There was also some discussion of the ICCA's rôle as the organization protecting the interests of chess programmers. In order to fulfil this rôle it

- must be credible

- must have a high profile

- must protect the titles it awards

- must have regular input from our FIDE liason officer (now Kevin O'Connell), who should be more readily identifiable and accessible.

9. The format of some past WMCCs was questioned. There were also complaints about the play-offs for the grand title at the WMCCs, a question which the ICCA should address. While the benefits of corporate participation were recognized, e.g., the opportunity to meet senior representatives from the commercial world, the complaint was also voiced that the manufacturers are now allowed to compete in all categories (Software, Hardware and Team), maximizing their chances for a good result, to the detriment of small software vendors barely emerging from amateur status. Nevertheless, once the President stressed the importance of these events to the ICCA's financial health (entry fees for commercial entrants combined with sponsorship income represent the ICCA's only regular method of acquiring necessary funds to support our activities!), the audience appreciated that idealistic, simple solutions might not be practical. One way of ensuring that the ICCA remains uncompromised is that all ICCA members help find sponsors for future ICCA events and inform Tony Marsland or David Levy of any interest that they have been able to generate.

Despite the over-emphasis in some presentations, this meeting was one of the more interesting and productive in recent years. At the close, the ICCA representatives thanked the members present for their up-beat and constructive contributions.

\title{
REPORT ON THE QMW UNIFORM-PLATFORM WORLD CHAMPIONSHIP 1994
}

\author{
D.F. Beal ${ }^{1}$ \\ Queen Mary and Westfield College \\ London, England
}

The Uniform Platform Championship runs all the programs on identical hardware. The idea is that ingenuity in software and improved algorithms are the only route to success in this event, rather than the sometimes huge differences in computer power used in other tournaments.

This year 16 programs took part, from 7 countries. Most entrants preferred to enter PC binaries, rather than $\mathrm{C}$ programs, so this year the $\mathrm{C}$ programs were compiled with a 32-bit $\mathrm{C}$ compiler, and run under DOS on the same machines. This avoided the need for two divisions. The machines used were eight Brother BCR-486/DX40Mhz machines with 8 MB RAM, loaned for the event by Kyodai UK Ltd.

In addition to the automated transmission of moves between programs during a game, as had been done in the two previous uniform-platform tournaments, the 1994 tournament had a computer to operate the computers!

The chess-playing PCs were connected to a network and powered via computer-controlled power sockets. Separate computers on QMW's network controlled the event. These controlling computers were equipped with various pieces of software that compiled a list of game pairings that had to be played, detected when games were over, powered down pairs of PCs, set up command scripts for them to execute, and powered

Queen Mary and Westfield College, Department of Computer Science, Mile End Road, London E1 4NS, England. Email: icca@des.qmw.ac.uk 